\title{
A New Pathotype of Pea seedborne mosaic virus Explained by Properties of the P3-6k1- and Viral Genome-Linked Protein (VPg)-Coding Regions
}

\author{
Charlotte Kristiane Hjulsager, Ole Søgaard Lund, and I. Elisabeth Johansen \\ Biotechnology Group, Danish Institute of Agricultural Sciences, Thorvaldsensvej 40, opg.8, 2. sal, DK-1871 Frederiksberg C, \\ Denmark
}

Submitted 17 July 2001. Accepted 10 October 2001.

\begin{abstract}
A fourth pathotype of Pea seedborne mosaic virus, a member of the genus Potyvirus, was identified by analysis of the infection profile on a panel of Pisum sativum lines. The new pathotype, designated P-3, was able to overcome resistance specified by the $s b m-1$ resistance gene but could not overcome resistance specified by the $s b m-2$ resistance gene. This infection profile distinguished $\mathbf{P}-3$ from previously described pathotypes, P-1, P-2, and P-4. Analysis of chimeric viruses demonstrated that properties of the P3-6k1- and viral genome-linked protein (VPg)-coding regions accounted for the infection profile of the new pathotype.
\end{abstract}

Pea seedborne mosaic virus (PSbMV) isolates are recognized as pathotypes $\mathrm{P}-1, \mathrm{P}-2$, and $\mathrm{P}-4$ by their infection profiles on a panel of Pisum sativum lines including both cultivars and plant introduction (PI) lines (Alconero et al. 1986; Kasimor et al. 1997). Correspondingly, P. sativum lines can be divided into categories A, B, C, and D, depending on their susceptibility to the PSbMV pathotypes (Johansen et al. 2001). Category A lines are susceptible to all three pathotypes, category B lines are resistant to all three pathotypes, category $\mathrm{C}$ lines are resistant only to pathotype P-2, and category D lines are resistant to pathotypes P-1 and P-2. Thus, categories C and D are sufficient to differentiate the three known pathotypes. Resistance to PSbMV in $P$. sativum is inherited as single recessive genes, designated $s b m-2$ and $s b m-1$ in category $\mathrm{C}$ and D lines, respectively (Johansen et al. 2001; Provvidenti and Alconero 1988a, 1988b). Infectious clones of isolates representing each pathotype are available (Johansen 1996; Olsen and Johansen 2001). The cDNAs representing pathotypes P-2 and P-4 are derived from the isolates L1 and NY, originally used to define these two pathotypes (Alconero et al. 1986), whereas the cDNA of pathotype P-1 is derived from the isolate DPD1 (Johansen et al. 1991).

The PSbMV isolate NEP1 (Andersen and Johansen 1998) was originally isolated from a Vicia faba seed sample from Nepal. To determine the pathotype of NEP1, the virus was manually inoculated to a panel of $P$. sativum lines representing categories A to D. At least six plants of each line were inocu-

Corresponding author: I. E. Johansen; Telephone: +45 3528 2584; Fax: +45 3528 2589; E-mail: e.johansen@ dias.kvl.dk

The nucleotide and amino acid sequence data reported are available in the EMBL database under the accession numbers AJ311841, AJ311842, and AJ311843. lated and tested for the presence of PSbMV coat protein by enzyme-linked immunosorbent assay (Kohnen et al. 1995) 3 weeks postinoculation. The observed infection profile of NEP1 differs from any of the previously described PSbMV pathotypes (Table 1). Like pathotype P-2, NEP1 did not infect category $\mathrm{C}$ lines, represented by cultivars Bonneville and Dark Skinned Perfection, but unlike pathotype P-2, NEP1 infected category D lines PI 269818 and PI 269774. Thus, NEP1 represents a new pathotype of PSbMV and we suggest the designation pathotype P-3 for PSbMV isolates with this infection profile on P. sativum.

Analysis of PSbMV chimeras generated from the three pathotypes P-1, P-2, and P-4 suggests that pathotype-specific infectivity on $P$. sativum lines of category $\mathrm{C}$ is determined by properties in the potyvirus $\mathrm{P} 3-6 \mathrm{k} 1$-coding region, while infectivity on category $\mathrm{D}$ lines is determined by properties in the $5^{\prime}$ half of the region encoding the viral genome-linked protein (VPg) (Johansen et al. 2001). Recessive resistance may reflect a lack of functional interaction between the virus-encoded pathogenicity determinant and the host factor encoded by the resistance gene. According to this hypothesis, NEP1-encoded P3-6k1 would not be expected to produce a functional interaction with the host factor encoded by $s b m-2$ in category $\mathrm{C}$ lines. NEP1-encoded VPg, on the other hand, is expected to produce a functional interaction with the $s b m$ - 1 -encoded host factor in category D lines as well as the corresponding factor in category $\mathrm{C}$ lines.

To determine if the infection profile of NEP1 could be explained by properties of the P3-6k1 region and the $5^{\prime}$ half of the $\mathrm{VPg}$ region $(\mathrm{VPgN})$, the $\mathrm{P} 3-6 \mathrm{k} 1-$ or $\mathrm{VPgN}$-coding region of $\mathrm{P}-1$ and P-4 infectious clones was replaced by the corresponding sequences from NEP1. NEP1 cDNA was synthesized from RNA templates extracted from $V$. faba and $P$. sativum using an oligo(dT) primer as described by Olsen and Johansen (2001). The P3-6k1- and VPgN-coding regions were amplified by polymerase chain reaction (PCR) using degenerate oligonucleotide primer pairs (pair 5'-GACIACIGGITAYCAYATHYTIAARGCNGG [in which I is inosine; $\mathrm{R}$ is $\mathrm{G}$ or $\mathrm{A}$; $\mathrm{Y}$ is $\mathrm{T}$ or $\mathrm{C}$; $\mathrm{H}$ is $\mathrm{A}$, $\mathrm{C}$, or T; and $\mathrm{N}$ is $\mathrm{G}, \mathrm{A}, \mathrm{T}$, or $\mathrm{C}$ ] and $5^{\prime}$-GTICKRTTYTGYTCCATYTGRTTYTGCCACCA [in which $\mathrm{K}$ is $\mathrm{G}$ or $\mathrm{T}$ ] and pair 5'-ATGTAYCARATHTTYATGGC and 5'-ACYCTCATNGGRTTRTGNGG, respectively). PCR products were cloned in TA-TOPO cloning vector pCRII-TOPO (InVitrogen, Groningen, The Netherlands). Nucleotide sequence reactions (ABI Prism BigDye Terminator Cycle Sequencing Ready Reaction Kit; Applied Biosystems, Nærum, Denmark) were analyzed on an 
automated ABI 377XL DNA sequencer (Applied Biosystems). The nucleotide sequence of the P3-6k1-coding region was unambiguous, whereas two variants of $\mathrm{VPgN}$ were identified. The variant $\mathrm{VPgN}-\mathrm{E}$, found in the majority of the sequences, had a glutamic acid codon (GAG) at nucleotides 316 to 318 of the predicted $\mathrm{VPgN}$-coding region. The $\mathrm{VPgN}-\mathrm{K}$ variant, found in cDNA derived from two different $P$. sativum plants, had a lysine codon (AAG) in this position. The NEP1 P3-6k1-coding sequence was modified to introduce a $K p n I$ restriction site $5^{\prime}$ and a HpaI site $3^{\prime}$ to the P3-6k1-coding region (using primers 5'-CGGGGTACCCAGAAAATGGAGCAAATTGAG and 5'GGGTTAACTTCTTGCCCCATTGTTGTGAA, restriction sites underlined). In addition, a PstI site was introduced at nucleotides 635 to 640 of the predicted P3-6k1-coding region for insertion of an intron as described in Johansen (1996). Similarly, an XhoI site was introduced 5' and a StuI site $3^{\prime}$ to the region encoding $\mathrm{VPgN}$ of both NEP1 VPgN-E and $\mathrm{VPgN}-\mathrm{K}$ (using primers 5'-GCTCGAGGGGAAATCAAAAGCCAAGAC and 5'-CGAGGCCTCAACTTTGGGGTTAAGCC). In a series of standard cloning steps, the P3-6k1- and VPgN-coding regions of modified P-4 NY and P-1 DPD1 full-length clones (Johansen et al. 2001) were replaced by the corresponding regions from NEP1.

Table 1. Infection profiles of Pea seedborne mosaic virus pathotypes P-1, $\mathrm{P}-2$, and $\mathrm{P}-4^{\mathrm{a}}$, and the proposed pathotype $\mathrm{P}-3$, represented by the isolate NEP1, on Pisum sativum lines representing categories A to D

\begin{tabular}{llcccc}
\hline & & \multicolumn{4}{c}{$\begin{array}{c}\text { Pathotypes } \\
\text { (isolate representing the pathotype) }\end{array}$} \\
\cline { 3 - 6 } Category & Pea line & (DP-1 & $\begin{array}{c}\text { P-2 } \\
\text { (DP1) }\end{array}$ & $\begin{array}{c}\text { P-4 } \\
\text { (NY) }\end{array}$ & $\begin{array}{c}\text { P-3 } \\
\text { (NEP1) }\end{array}$ \\
\hline $\mathrm{A}$ & Fjord & $\mathrm{S}^{\mathrm{b}}$ & $\mathrm{S}$ & $\mathrm{S}$ & $12 / 12^{\mathrm{c}}$ \\
& Brutus & $\mathrm{S}$ & $\mathrm{S}$ & $\mathrm{S}$ & $8 / 8$ \\
$\mathrm{~B}$ & PI 193586 & $\mathrm{R}^{\mathrm{d}}$ & $\mathrm{R}$ & $\mathrm{R}$ & $0 / 8$ \\
& PI 347492 & $\mathrm{R}$ & $\mathrm{R}$ & $\mathrm{R}$ & $0 / 8$ \\
$\mathrm{C}(s b m-2)$ & Bonneville & $\mathrm{S}$ & $\mathrm{R}$ & $\mathrm{S}$ & $0 / 6$ \\
& DSP & $\mathrm{S}$ & $\mathrm{R}$ & $\mathrm{S}$ & $0 / 12$ \\
$\mathrm{D}(s b m-1)$ & PI 269774 & $\mathrm{R}$ & $\mathrm{R}$ & $\mathrm{S}$ & $4 / 8$ \\
& PI 269818 & $\mathrm{R}$ & $\mathrm{R}$ & $\mathrm{S}$ & $10 / 12$ \\
\hline
\end{tabular}

${ }^{\mathrm{a}}$ Olsen and Johansen 2001.

${ }^{\mathrm{b}} \mathrm{S}$ = susceptible, virus coat protein detectable by enzyme-linked immunosorbent assay (ELISA) in upper noninoculated leaves, 3 weeks postinoculation.

${ }^{c}$ Number of ELISA-positive plants per number of plants tested.

${ }^{\mathrm{d}} \mathrm{R}=$ resistant, virus coat protein not measurable by ELISA in upper noninoculated leaves, 3 weeks postinoculation.

${ }^{\text {e }}$ P. sativum cultivar Dark Skinned Perfection.

Table 2. Infection profiles of Pea seedborne mosaic virus chimeras P-4 ${ }^{\text {NEP1 }}$ P3-6k1 and P-1 ${ }^{\text {NEP1 VPgN-E }}$ on Pisum sativum lines Brutus, Dark Skinned Perfection, and PI 269818 representing categories A, C, and D

\begin{tabular}{lccccc}
\hline \multirow{2}{*}{$\begin{array}{l}\text {. sativum } \\
\text { category }\end{array}$} & \multicolumn{2}{c}{ P-4 $^{\text {NEP1 P3-6k1 }}$} & & \multicolumn{2}{c}{ P-1 $^{\text {NEP1 VPgN-E }}$} \\
\cline { 2 - 3 } \cline { 5 - 6 } & ELISA $^{\mathbf{a}}$ & GUS $^{\mathbf{b}}$ & & ELISA $^{\mathbf{a}, \mathbf{c}}$ & $\mathbf{G U S}^{\mathbf{b}, \mathbf{d}}$ \\
\hline $\mathrm{A}$ & $8 / 8$ & $18 / 18$ & & $12 / 12$ & $18 / 18$ \\
$\mathrm{C}($ s $b m-2)$ & $0 / 23$ & $0 / 18$ & & $12 / 12$ & $18 / 18$ \\
$\mathrm{D}($ s $b m-1)$ & $12 / 12$ & $11 / 11$ & & $12 / 12$ & $12 / 12$ \\
\hline
\end{tabular}

${ }^{\text {a }}$ Number of enzyme-linked immunosorbent assay (ELISA)-positive plants per number of plants tested. Plants were inoculated with sap from plants infected with untagged viruses.

${ }^{\mathrm{b}}$ Number of plants with $\beta$-glucuronidase (GUS) staining per number of plants tested. Plants were inoculated by particle bombardment with GUS-tagged cDNA constructs. All positive plants showed GUS staining in both inoculated and upper noninoculated leaves.

${ }^{\mathrm{c}}$ Identical results were obtained with P-4 $4^{\mathrm{NEP} 1} \mathrm{VPgN}-\mathrm{E}, \mathrm{P}-4^{\mathrm{NEP} 1 \mathrm{VPgN}-\mathrm{K}}$, and $\mathrm{P}-1^{\mathrm{NEP} 1} \mathrm{VPgN}-\mathrm{K}$

d Identical results were obtained with P-1GUS ${ }^{\text {NEP1 VPgN-K. }}$
Infectivity of the resulting chimeric viruses $\mathrm{P}-4^{\mathrm{NEP} 1} \mathrm{P} 3-6 \mathrm{k} 1$, $\mathrm{P}-1^{\mathrm{NEP} 1 \mathrm{VPgN}-\mathrm{E} / \mathrm{K}}$, and P-4 ${ }^{\mathrm{NEP} 1 \mathrm{VPgN}-\mathrm{E} / \mathrm{K}}$ were analyzed on $P$. sativum category A, C, and D lines (Table 2). We observed, that while P-4 is infectious on category A, C, and D plants, the chimeric virus P-4 ${ }^{\text {NEP1 }}$ P3-6k1 did not infect category $C$ plants. Thus, replacing the $\mathrm{P} 3-6 \mathrm{k} 1$ region of $\mathrm{P}-4$ with the corresponding NEP1 sequence resulted in an altered infectivity on category $C$ plants but not on category D plants. Like P-4, the chimeras

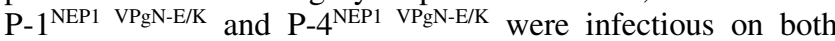
category $\mathrm{C}$ and category $\mathrm{D}$ plants. Thus, replacing the VPgNcoding region with the corresponding NEP1 sequence did not alter infectivity on category $\mathrm{C}$ plants. In contrast, $\mathrm{P}-1$ is not in-
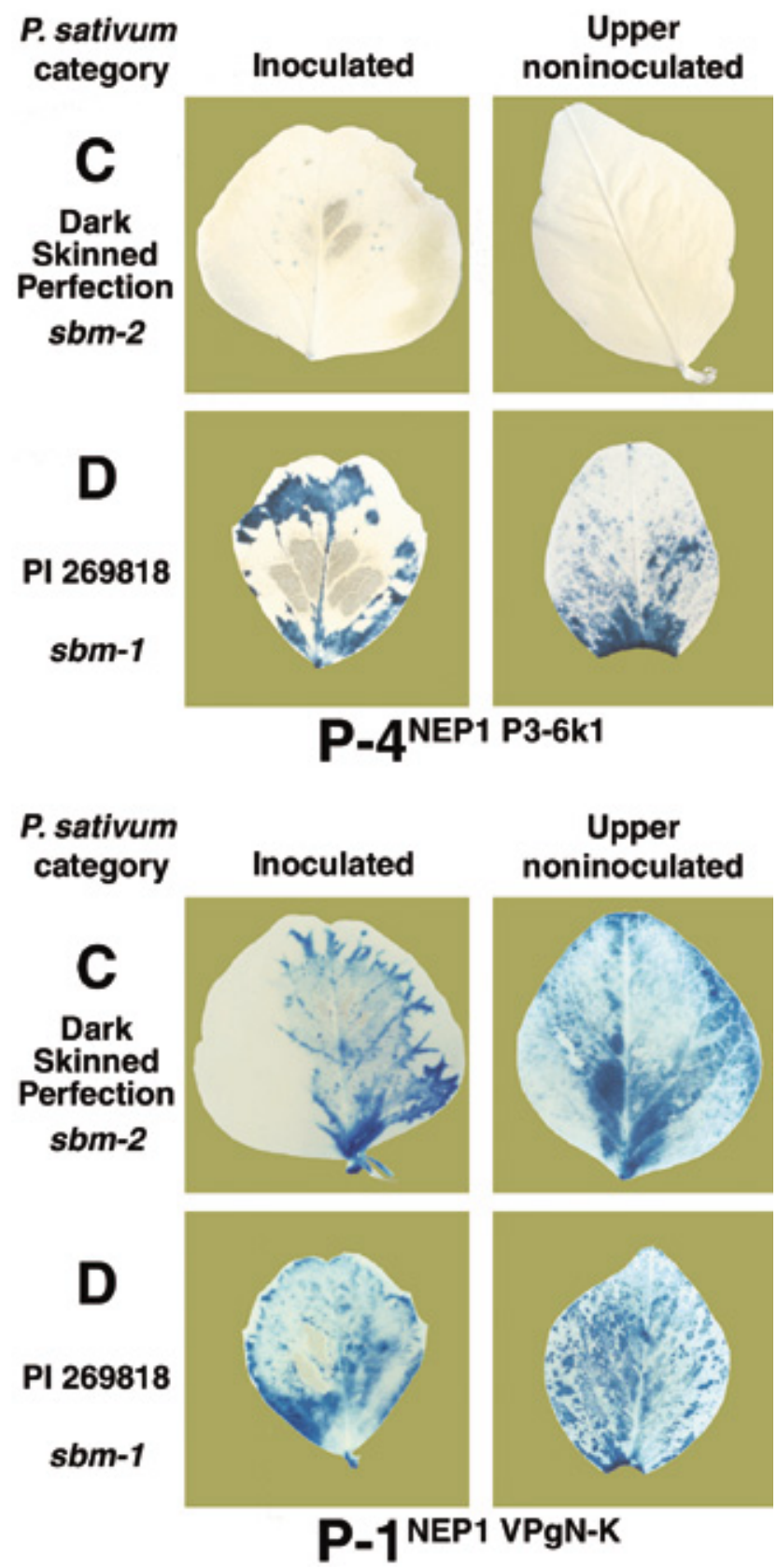

Fig. 1. In situ $\beta$-glucuronidase (GUS) assays, 2 weeks postinoculation, of Pisum sativum leaves from plants inoculated with GUS-tagged Pea seedborne mosaic virus constructs P-4GUS ${ }^{\mathrm{NEP} 1 \mathrm{P} 3-6 \mathrm{k} 1}$ and P-1GUS ${ }^{\mathrm{NEP} 1 \mathrm{VPgN}-\mathrm{K}}$. Inoculated leaves (left) and upper noninoculated leaves (right) of category C plants, homozygous for the recessive resistance gene $s b m-2$, are shown in the first and third rows. Category D plants, homozygous for the recessive resistance gene $s b m-1$, are shown in the second and fourth rows. 
fectious on category D plants, but replacing the VPgN-coding region with the corresponding NEP1 sequence resulted in a chimera that was infectious on category D plants (Table 2). The codon difference at nucleotides 316 to 318 corresponds to amino acid 106 of PSbMV VPg. Although this is within the region that determines pathotype-specific infectivity of P-1 and P-4 on category D lines (Borgstrøm and Johansen 2001), we did not observe any difference in infectivity of the VPgN-E and $\mathrm{VPgN}-\mathrm{K}$ variants of $\mathrm{P}-1^{\mathrm{NEP} 1 \mathrm{VPgN}}$ and $\mathrm{P}-4^{\mathrm{NEP} 1 \mathrm{VPgN}}$.

To visualize the infection, the chimeras were tagged with the $\beta$-glucuronidase (GUS) reporter gene as described before (Borgstrøm and Johansen 2001). Plasmid DNA from GUStagged constructs P-4GUS ${ }^{\mathrm{NEP} 1}{ }^{\mathrm{P} 3-6 \mathrm{k} 1}$ and P-1GUS ${ }^{\mathrm{NEP} 1} \mathrm{VPgN-E/K}$ were inoculated by particle bombardment to category A, C, and $\mathrm{D}$ plants, and virus infection was visualized by in situ histochemical GUS assays (Dolja et al. 1992). On inoculated leaves, extensive GUS staining was observed 1 week postinoculation upon bombardment with P-1GUS ${ }^{\mathrm{NEP} 1}$ VPgN on category A, C, and D plants and on category A and D plants inoculated with P-4GUS ${ }^{\mathrm{NEP} 1 \mathrm{P}-6 \mathrm{k} 1}$. In contrast, inoculated leaves of category $\mathrm{C}$ plants bombarded with P-4GUS ${ }^{\text {NEP1 P3-6k1 }}$ displayed small blue inoculation foci of the same size and intensity as observed with a replication defective PSbMV construct (Borgstrøm and Johansen 2001). Observations at later timepoints showed a progressive spread of GUS staining on category A, C, and D plants bombarded with P-1GUS ${ }^{\mathrm{NEPI} V P g N}$ and on category A and D plants bombarded with P-4GUS ${ }^{\mathrm{NEP} 1}$ P3-6k1, whereas inoculation foci on category $\mathrm{C}$ plants bombarded with P-4GUS ${ }^{\mathrm{NEP} 1 \mathrm{P} 3-6 \mathrm{k} 1}$ did not expand further. The GUS-stained inoculation foci on leaves of category $\mathrm{C}$ plants bombarded with the P-4GUS ${ }^{\mathrm{NEP} 1}$ P3-6k1 construct were of the same size and intensity as those on category C plants bombarded with P-2GUS or P-4GUS ${ }^{\mathrm{P}-2} \mathrm{P3}-6 \mathrm{k} 1$ (Johansen et al. 2001). This observation is in agreement with the hypothesis that PSbMV pathotypes P-2 and P-3 are affected by the same resistance mechanism mediated through the P3-6k1 protein. Figure 1 shows leaves assayed 2 weeks postinoculation.

The results presented here demonstrate that a previously predicted fourth pathotype of PSbMV (Johansen et al. 2001) can be found in natural populations. Furthermore, the observations are in agreement with a model explaining the infection profiles of PSbMV pathotypes exclusively by properties of the P3-6k1 and $\mathrm{VPgN}$ regions (Johansen et al. 2001). The possibility that other parts of the NEP1 genome affect the observed infection profile cannot be excluded, because the reciprocal chimeric viruses in an NEP1 background are not available for testing. However, our results support the idea that pathotype-specific infection of category $C P$. sativum lines, homozygous for the recessive resistance gene $s b m-2$, depends on properties of the P3-6k1 region; while pathotype-specific infection of category $\mathrm{D}$ lines, homozygous for the recessive resistance gene $s b m-1$, depends on properties of the VPgN region.

\section{ACKNOWLEDGMENTS}

We thank S. E. Albrechtsen, Danish Government Institute of Seed Pathology for Developing Countries, for providing the Pea seedborne mosaic virus isolate NEP1 and B. S. Olsen for expert technical assistance. This work was supported by the Danish Agricultural and Veterinary Research Council grant 9702802 and EU grant CT97-2356.

\section{LITERATURE CITED}

Alconero, R., Provvidenti, R., and Gonsalves, D. 1986. Three pea seedborne mosaic virus pathotypes from pea and lentil germ plasm. Plant Dis. 70:783-786.

Andersen, K., and Johansen, I. E. 1998. A single conserved amino acid in the coat protein of pea seed-borne mosaic potyvirus modulates the ability of the virus to move systemically in Chenopodium quinoa. Virology 241:304-311.

Borgstrøm, B., and Johansen, I. E. 2001. Mutations in Pea seedborne mosaic potyvirus genome-linked protein VPg alter pathotype-specific virulence in Pisum sativum. Mol. Plant-Microbe Interact. 14:707-714.

Dolja, V. V., McBride, H. J., and Carrington, J. C. 1992. Tagging of plant potyvirus replication and movement by insertion of $\beta$-glucuronidase into the viral polyprotein. Proc. Natl. Acad. Sci. U.S.A. 89:10208-10212.

Johansen, I. E. 1996. Intron insertion facilitates amplification of cloned virus cDNA in Escherichia coli while biological activity is reestablished after transcription in vivo. Proc. Natl. Acad. Sci. U.S.A. 93: 12400-12405.

Johansen, I. E., Rasmussen, O. F., Heide, M., and Borkhardt, B. 1991. The complete nucleotide sequence of pea seed-borne mosaic virus RNA. J. Gen. Virol. 72:2625-2632.

Johansen, I. E., Lund, O. S., Hjulsager, C. K., and Laursen, J. 2001. Recessive resistance in Pisum sativum and potyvirus pathotype resolved in a gene-for-cistron correspondence between host and virus. J. Virol. 75:6609-6614.

Kasimor, K., Baggett, J. R., and Hampton, R. O. 1997. Pea cultivar susceptibility and inheritance of resistance to the lentil strain (pathotype P2) of pea seedborne mosaic virus. J. Am. Soc. Hortic. Sci. 122:325328.

Kohnen, P. D., Johansen, I. E., and Hampton, R. O. 1995. Characterization and molecular detection of the P4 pathotype of pea seedborne mosaic potyvirus. Phytopathology 85:789-793.

Olsen, B. S., and Johansen, I. E. 2001. Nucleotide sequence and infectious cDNA clone of the L1 isolate of Pea seed-borne mosaic potyvirus. Arch. Virol. 146:15-25.

Provvidenti, R., and Alconero, R. 1988a. Inheritance of resistance to a lentil strain of pea seed-borne mosaic virus in Pisum sativum. J. Hered. 79:45-47.

Provvidenti, R., and Alconero, R. 1988b. Inheritance of resistance to a third pathotype of pea seed-borne mosaic virus in Pisum sativum. J. Hered. 79:76-77. 